dicated, tend to bedevil its use in an evolutionary setting. It is largely these wisps from the past that have caused so much controversy over the relationship between nomenclatural and experimental taxonomy. The problem of whether to adapt or to abandon a particular term is a familiar one in the history of thought, and which course should be taken depends on the adaptability of the term and the extent of the change that has taken place. For example, the humours of medieval medicine developed quite happily into the present-day bad and good humour of our dispositions, whereas phlogiston, which could not be adapted to modern science, is dead-and the word 'dryads' is not now employed to explain the behaviour of Quercus robur. On balance, the abandonment of the term 'species' as a category to express the findings of experimentel taxonomy, reflecting a clean break with the non-evolutionary past, would seem to be the right policy. The reluctance of geneticists and others to take this step is, perhape, bound up with a lingering belief that species are, in some way, 'real entities', not 'artificial constructs of the human mind' as are other taxa. This belief makes it seem unthinkable to abandon the term for such an important branch of biology as the study of micro-evolution. If, however, 'real entities' and 'artificial constructs' are regarded, not as mutually exclusive, but as alternative descriptions, each valid in its own context, this difficulty disappears. Such an approach has recently been fully developed by $R$. Crawshay-Williams in a most stimulating books.

The policy I am advocating is strongly reinforced by a consideration of the continued use of the term in nomenclatural taxonomy. Clearly, there will always be a need for a general-purpose classification, based primarily on morphology, for those who require a broad map of the diversity of living things. For this purpose, the nomenclatural categories of genus, species, variety, etc., are excellently suited, and it would be a great advantage if they were not subject to continued attempts to bring them up to date and to re-define them in evolutionary terms. Let them be regarded, frankly, as mainly morphological categories based on degree of difference and they will perform their proper function in biological classification. Such a view would lead to a reduction in the number of name changes made for taxonomic, as opposed to nomenclatural, reasons. For if it was agreed that genera and species should be regarded as broad, flexible categories, with a considerable element in them of convenience, biologists would not be so constrained to alter the limits of existing taxa in order to fit them to a particular taxonomic theory. This policy will, I know, strike many biologists as lessening the stature and importance of nomenclatural taxonomy. This is true only in the sense that, at the specific, or in some cases the generic, level detailed micro-evolutionary knowledge, when available, would be embodied in special categories, leaving the nomenclatural categories free to give a general purpose account of the variation of the organisms concerned. This does not mean, however, that attributes such as intersterility and chromosome number would be rigidly excluded as criteria for the nomenclatural categories; if they can be incorporated as supplementary to morphology without destroying the general utility of the classification the additional information thus embodied would be, of course, a valuable asset.

The suggestions outlined in this communication are an attempt to crystallize into a definite policy some of the rather ill-defined ideas that are in the air on the defects of present-day taxonomic theory and practice. They are put forward in the hope that others will be stimulated to think about them and discuss them, too, with the view of evolving a generally agreed policy.

${ }^{1}$ Camp, W. H., Brittonia, 7, 113 (1951).

${ }^{2}$ Gilmour, J. S. L., Nature, 168, 400 (1951).

${ }^{8}$ Gilmour, J. S. L., and Heslop Harrison, J., Genetica, 27, 147 (1964).

"Species Studies in the British Flora", 160, 173 (Bot. Soc. Brit. Isles, London, 1955).

"Crawshay-Williams, R., "Methods and Criteria of Reasoning" (Routledge and Kegan Paul, 1957).

\title{
PHYSICS OF WATER AND ICE
}

T HE discussion on "The Physics of Water and Ice", held at the Royal Society on November 14, was particularly timely. In the past two years there has been a renewed interest in both the ex. perimental and theoretical aspects of ice and water in relation to their physical properties and their structure. On the theoretical side it has been evident for some time that the picture of ice and water as essentially regular and irregular arrangements, respectively, of water molecules tied together tetrahedrally by hydrogen-bonds is only a rough first approximation. Certainly it is inadequate for the degree of detail now required to define the properties of these substances. It is especially true for the properties that are so-called 'structure sensitive', that is, that depend on the variation of the crystalline material from its ideal state. At the same time, the practical interest in ice and water has been increasing from a number of fields, notably from glaciology, from the technical aspects of the icing of aircraft and aircraft engines, and perhaps most of all from meteorology, where it is now evident that the processes of conversion of water-drops into ice is funda- mental for the phenomena of rain and thunderstorms. In the latter connexion it is interesting that a new type of interdepartmental co-operative research has now been going for three years at the Imperial College of Science and Technology, London, some of the main results of which were reported at the meeting. The meeting was not primarily concerned with the theoreticel aspects of the hydrogen-bond, which hed been recently covered in a discussion of the Section of Physical Chemistry of the International Union of Chemistry, at Ljubljana; nor with that of aqueous solutions, also recently dealt with at the Faraday Society meeting at Oxford. However, some of the leading Continental experts attending both those conferences also took part in the Royal Society discussion, and gave more details of their work in the field of pure water and ice.

Underlying all studies of ice is the knowledge of its structure at different temperatures. A critical survey of the data now available was given by Dame Kathleen Lonsdale (University College, London) in the opening paper, in which she discussed the results of the latest $\mathrm{X}$-ray, electron and neutron diffraction experiments, 
both for ordinary and for heavy ice. Both substances show some degree of differential contraction along the $a$ - and $c$-axes on cooling, tending to make all the intermolecular distances of the water molecules in ice more nearly equal at the lower temperatures. This result, however, seems to contradict that reported by Dr. R. W. Powell, of the National Physical Laboratory, on the basis of careful interferometric measurements of the coefficient of expansion of large single crystals of ice in two directions. Such discrepancies, however, are not unknown in other instances, and there seems to be a systematic difference between $\mathrm{X}$-ray and macroscopic measurements of thermal expansion, possibly due to crystal imperfections. However, the work ought to be repeated by both methods, preferably on the same specimen.

The neutron-diffraction work of $H$. A. Levy, of which a report was heard at the Discussion, indicates an almost completely random position for the protons along the hydrogen-bonds, corresponding to the picture given by Pauling, but Dame Kathleen Lonsdale pointed out that slight deviations from randomness could not easily be detected by this method.

Dr. G. B. B. M. Sutherland reported studies on the infra-red absorption of single crystals of ice, which he had carried out in conjunction with Dr. Ockmann. Over most of the frequencies concerned there seem to be very little preferred orientation and this would also favour an almost isotropic random hydrogenbond structure for ice.

Prof. W. C. Price (King's College, London) reported some infra-red absorption studies of water adsorbed on alkali halides. Observed shifts in the frequencies of the $3,000-\mathrm{cm} .^{-1}$ band were interpreted in terms of water molecules attached by hydrogen-bonds to the negative ions. With thicker layers of adsorbed water, bands appear in the 2,000-cm. ${ }^{-1}$ region, corresponding to molecular deformation plus a libration of the molecule against the forces of association with other molecules. Body-centred alkali halides show additional bands which suggest attachment of water to positive ions.

Dr. G. J. C. Frohnsdorff and Dr. G. L. Kington, working in Prof. R. M. Barrer's department in the Imperial College, reported some interesting thermodynamic and spectroscopic properties of water contained in the pores of synthetic zeolites, where up to twenty-one molecules of water can be accommodated. Here a transition can be observed between a predominantly adsorbed pattern on slight hydration, to a water-like pattern occurring close to saturation.

An important paper was read by Dr. H. Gränicher, reporting the studies of the Zurich school on the relaxation process, particularly dielectric relaxation in ice. Dr. Gränicher attributes part only of these phenomena to the presence of hydrogen ions in the form of oxonium and hydroxyl ions. He also postulates the presence of what he calls $L$ - and $D$-protonic defects in ice in which the oxygen atoms are only slightly displaced. $L$-defects consist of two neighbouring oxygen atoms between which there is no proton; in $D$-defects two protons are more or less collinearly arranged between oxygen atoms. These types of defects are essumed to wander through the crystial structure, to be created and to neutralize each other. In this way good agreement is achieved with the new experimental results on the variation with frequency of the dielectric constant of ice at different temperatures. A theoretical treatment of lattice defects in relation to the mechanical relaxation of ice was given by Dr. R. Bass of Stuttgart.
The work of the Göttingen school was presented by Dr. L. De Mayer--Dr. M. Eigen, who is largely responsible for it, being unfortunately too ill to attend. It has long been known that the electrical conductivities of pure water and pure ice are of the same order of magnitude, and it is assumed that this is because the mechanisms operating in the two cases are similar. The Göttingen workers have managed to measure separately the number of ionic carriers, namely $\left(\mathrm{OH}_{3}\right)^{+}$and $(\mathrm{OH})^{-}$groups, and their apparent velocities. They find that the number in ice is only a small fraction of that in water, and consequently the apparent velocity of hydrogen ions in ice must be many times as great as in water. As the velocity of hydrogen ions in water is already much higher than that of any other ion, and is clearly due, as Fowler and Bernal showed twenty-five years ago, by some form of relay mechanism, proton-transfer in ice must be by a similar mechanism, operating not over one hydrogen-bond but over a chain of hydrogenbonds. This is very similar to electron-transfer in metals, and a close analogy exists between the two phenomena. It is even possible, by the introduction of fluorine ions, to produce what are equivelent to $p$ - and $n$-junctions for ice, with protons taking the role of electrons in semiconductors. This work obviously opens up a very exciting field of theory which may have particular application in biology, following some recent suggestions by SzentGyörgyi.

Prof. H. S. Frank (United States) discussed the significance of some of the results already reported in terms of the nature of the hydrogen-bonds in water and ice, pointing out that the influence of the bond itself on the lone-peir electrons on the other side of the molecule leads to a general strengthening of the bond, and provides some explanation for the closer approximation of the properties along the $a$ - and $c$ axes at low temperatures. This also goes some way to explain the very peculiar fact that the cubic form of ice, which has a diamond structure at first sight essentially similar to the wurzite structure of hexagonal ice, is not stable above $-110^{\circ} \mathrm{C}$.

Turning now to the structure of water, Dr. C. L. van Pantaleon van Eck reported some very careful work recently carried out at Amsterdam on the X-ray diffraction patterns of water and on its infrared absorption. His conclusions are that in the waterstructure there are approximately six molecular neighbours at distances varying from $3 \cdot 0$ to $3 \cdot 4 \mathrm{~A}$. from any given molecule. It is not clear why this result is different from that obtained by Warren and Morgan in 1938, who found four molecular neighbours at $2 \cdot 85 \mathrm{~A}$. Dr. van Eck's interpretation would imply a collapsed tetrahedral structure not unlike that of metallic tin in relation to grey tin. $\mathrm{He}$ bases an independent celculation of the intermolecular distance in water on the absorption spectrum of $\mathrm{HDO}$, in which the band at $3,500 \mathrm{~cm}^{-1}$, unlike the corresponding bands for ordinary and heavy water, is free from overlapping and permits an estimate leading to the value $2.85 \mathrm{~A}$., as opposed to the hydrogen-bond distance of $2.76 \mathrm{~A}$. found for ice. If this is the case then the hydrogen-bond in water would be considerably weaker than that in ice, of the order of 5 instead of $6 \mathrm{kcal}$./bond mole, and it would not be necessary to postulate any actual breaking of hydrogen-bonds on melting. These results throw open once more the whole question of the structure of water, and clearly much more experiment and calculation are necessary. 
Dealing with the transitions from water to ice, and from water-vapour to ice, two papers were read by Dr. B. J. Mason, representing the work of the Imperial College group. In the first Dr. Mason gave a full acount of the extremely beautiful method which he has developed for growing small crystals of ice at controlled temperatures and water-vapour concentrations in a thermal-gradient air box. He has shown that temperature alone determines the particular habit adopted by ice crystals, except at high supersaturation when dendritic growth occurs. In the temperature ranges from $0^{\circ}$ to $-3^{\circ} \mathrm{C}$., from $-8^{\circ}$ to $-12^{\circ} \mathrm{C}$. and from $-16^{\circ}$ to $-25^{\circ} \mathrm{C}$., hexagonal plates are the rule. On the other hand, from $-3^{\circ}$ to $-8^{\circ} \mathrm{C}$., and below $-25^{\circ} \mathrm{C}$., the predominant form is either the elongated hexagonal prism or the hollow prism which sometimes has a spiral structure. The fern-like dendritic crystals occur only between $-12^{\circ}$ and $-16^{\circ} \mathrm{C}$. By growing crystals successively at different temperatures Dr. Mason has succeeded in producing combined forms which reproduce many of the beautiful effects long known in snowflekes, which may be interpreted as indicating the various temperature regimes through which the snowflakes moved during their formation. These observations are of fundamental meteorological importance and also of great physical interest, because until now very little work has been done on the influence of temperature on crystal-form, and it would appear that the sharp changes of habit with temperature indicate that we are dealing here with a thermodynamic phenomenon depending on the relative values of the free energy of growth in different habits, as Prof. J. D. Bernal suggested at the meeting.

Dr. Mason's other peper described a series of carefully controlled experiments, on the supercooling and freezing of water drops. He showed two curves relating the volumes of drops to the temperatures at which they froze- one for freezing induced by nuclei, and another for the case in which nuclei are absent. In the latter case supercooling for drops as small as $1 \mu$ in diameter can be effected down to $-41^{\circ} \mathrm{C}$. and for $1-\mathrm{mm}$. drops down to $-33^{\circ} \mathrm{C}$. Crystallization at these temperatures is an almost explosive process, resulting in the fracture of the frozen droplet and its shattering, a phenomenon which may be of great importance for the rapid spread of nucleation through super-cooled clouds in the atmosphere.

Dr. M. Blackman (Imperial College, London) reported a study by electron diffraction of epitaxial growth of ice on silver iodide crystals. Silver iodide is the only substance at present known to be capable of producing rapid nucleation of ice. By controlled growth of single crystals of ice, Dr. Blackman has been able to show the crystal formation of the ice with sufficient penetration to bring out the underlying silver iodide lattice.
J. D. Bernal

\section{MIDDLE EAST TECHNICAL UNIVERSITY, ANKARA}

\section{BY Dr. TURGUT YAZICIOGLU}

$\mathrm{T}$ HE foundation stone of the Middle East Technical University in Ankara was laid on October 3, 1957, in the presence of the President of the Turkish Republic, the Prime Minister, the Minister of Education, the heads of the foreign aid committees, the Ambassedors of Great Britain and of the United States of America and other distinguished guests.

The University has, in fact, been working tem. porarily in a building in Ankara for two years. In 1956 there were 175 students attending the Colleges of Architecture and Administration, and in February 1957 the College of Engineering was established, followed in September by the creation of a research department for nuclear physics.

Foundations for colleges of mining, geology, agriculture and forestry were laid in 1956, and in 1958 students of electrical engineering, mining and geology will be admitted.

There are at present five foreign professors at the University, but arrangements have been made for further staff to be recruited through the United Nations (including two professors of architecture and one of administration), through Unesco (including professors of construction engineering, and of machinery), and through the technical aid programme of the British Government (professors of physics and of electrical engineering).

Thus by this year there will be altogether twelve foreign professors on the University staff; the Turkish teaching staff will number thirty.

The site designated for the construction of the Middle East Technical University is about three miles from Ankara and covers an area of about
4,500 hectares ( 11,115 acres). The University campus will comprise, besides the college buildings, dormitories, faculty bousing, libraries, a theatre, sports grounds, restaurants and other accommodation. All the plans and projects have been drawn up by the Turkish Ministry of Works in co-operation with the University of Pennsylvania.

According to the first ten-year programme, the University will have about 6,000 students, 2,500 teaching and research staff, and forty departments (including teaching and research units) at the end of the first decade.

During this ten-year period the Turkish Government is to make grants to the University totalling 265 million Turkish lira (about $£ 33$ million), of which almost half will be invested, while over the same period foreign aid will be available to a total of 26.5 million dollars. In addition, the British Ambassador, in his speech during the inaugural ceremony, promised a further sum of $£ 25,000$ from the British Government in the present year.

The University is designed to fulfil the need for an international centre of higher learning to serve the requirements of the developing Middle East. It is founded on the belief that the development of the region in a manner satisfying the demands of a progressive society requires the integration of techniques with human neods and aspirations. The University considers its major responsibility to be the training of a growing number of educated men and women, able to work creatively on the problems of the Middle East, using the most advanced techniques of our era. 